\title{
Research on Teaching Reform of Economic Mathematics of Economic Management Majors
}

\author{
Hui Sun, Wei Xu \\ Xi'an Eurasia University. Xi'an, Shaanxi, 710065, China
}

Keywords: Teaching reform, Economic mathematics, Economic management majors

\begin{abstract}
Economic mathematics is a basic mathematics course offered by economics and management majors in colleges and universities. It is an important carrier for cultivating the university's physiological thinking character and speculative ability, and it is an important means to develop the potential initiative and creativity of college students. Current economic mathematics teaching should be comprehensively explored and reformed in terms of curriculum settings, curriculum content, teaching methods, teaching models, and teaching evaluation.
\end{abstract}

\section{Introduction}

With the continuous improvement of the educational philosophy of higher education institutions in recent years, the practice teaching system of higher education institutions with the core purpose of cultivating practical talents has become the mainstream, which has made higher education institutions pay more and more attention to society. The Ministry of Education also clearly stated in "Several Opinions on Deepening Higher Vocational Education Reform Guided by Employment": "The most fundamental standard for running a college or university is to cultivate all types of highquality talents welcomed by society. Higher occupations Colleges and universities should be based in the field of higher vocational education, with clear characteristics of running a school, excellent talent training quality and high graduate employment rate to win social recognition and respect.

" With the continuous deepening of the reform of various professional courses, the reform of mathematics courses is also being explored. For a long time, the course "Economic Mathematics" in colleges and universities has been positioned as an important basic course for economics and management majors. It is not only a tool for subsequent courses but also an indispensable foundation for constructing students' scientific thinking structure. However, the idea of teaching reform with the direction of "enough theory and outstanding professional skills training" gradually becoming the mainstream of teaching reform, on the one hand, it has greatly reduced the teaching hours of courses, on the other hand, it has greatly reduced the requirements for teaching theory. The degree of correlation between economic mathematics and professional courses is getting lower and lower, and the role of economic mathematics as a follow-up professional course service is increasingly weakened. As a result, economic mathematics courses are first impacted. Many colleges and universities have taken lessons in mathematics teaching and reduced teaching. Content to resolve the contradiction of less class time, resulting in superficial and simplified mathematics content, some colleges simply canceled economic mathematics courses. However, the role of economic mathematics as an important tool for economic management, financial analysis, etc. still exists. Therefore, the foothold of the reform of economic mathematics teaching needs to be repositioned in order to pave the way for the reform of economic mathematics curriculum.

\section{Current Situation of Economic Mathematics Teaching in Colleges and Universities}

In nowadays, there are many teaching contents and a large amount of teaching tasks are required, and the teaching time of economic mathematics courses in colleges and universities is relatively small, and students cannot complete the study of these contents in a systematic and comprehensive manner. This also increases the difficulty of teaching teachers, and needs to choose the content of the teaching; the second is the application content in economic management involves less, and 
colleges and universities Students generally have poor theoretical foundations and high practical requirements. Therefore, it is difficult for students to preview before class and review after class, which is not conducive to improving students' motivation.

Students' learning goals are unclear and their attitudes are not correct. In most interviews, the problem exposed by students is that the learning purpose is not clear, which leads to an incorrect learning attitude. The second reason is that students cannot clearly find the relationship between mathematics and other professional courses. Although the instructors have repeatedly emphasized that economic mathematics is a professional basic course for economic management majors, but because the application case is less involved in the teaching process, the student's consciousness More indifferent. The third reason is that university teachers do not frequently review assignments after class. In addition, students' consciousness of learning is not high, so the quantity and quality of assignments after class are greatly reduced.

Teachers shall not teach in appropriate ways. Due to the limitation of teaching materials and teaching time, economic mathematics teachers usually use traditional teaching methods to teach students when they teach students, that is, they are still based on formulas and theoretical teaching, but there are very few talks about practice and application. In the specific teaching process, the teacher is superior, using the student's “orientation” and the teacher's "sense of knowledge first” and "expertise in the profession" knowledge authority, using the student's main task to learn as an excuse, consciously or not Consciously impose knowledge on students as something like a "decree" in a simple or even rude manner. At the same time, teachers focus on the content of theoretical parts such as formula derivation, and rarely or at all involve the application of economic mathematics formulas, laws, and thinking in practice, so they have not caused students to pay attention to ideas and methods.

The ability of students to apply what they have learned is rather lacking. The students' practical application ability is relatively lacking, manifested as follows: first, the basic mathematical theory is not well grasped, the knowledge is not solid, and the formula memory is not clear, such as in specific applications such as elastic analysis, market research, sampling survey, normal distribution, etc. Helpless, not to mention the difficult application of mathematical models such as the study of economic phenomena; second, in the study of professional courses, students show lack of rigorous thinking and deduction ability in mathematics, such as in operations research courses For the derivation of decision theory or model, most students rely on intuitive impressions and do not know how to use probability and mathematical statistics. This shows that there are many problems in the teaching of economic mathematics in economics and management majors in colleges and universities.

\section{Several Models of Current Economic Mathematics Teaching Reform}

The reform model based on the reorganization of mathematical content based on advanced mathematics This reform idea is to delete some knowledge of calculus, moderately reduce teaching requirements, increase the content of linear algebra and probability statistics, and some textbooks also add linear programming and other content. And add some economic cases. This model is adopted by most institutions. With the comprehensive deepening of the professional curriculum reform, the contradictions between the wide and scattered mathematics content and the high application requirements, the drastic reduction in teaching hours, and the decline in students' mathematical quality have become increasingly prominent.

The reform model focusing on enhancing mathematics to serve the needs of subsequent professional courses This model incorporates some examples abstracted from professional applications in the teaching content of mathematics, in order to reflect the role, approaches and methods of economic mathematics in professional applications. To some extent, it has changed the situation where economic mathematics and professional curriculum teaching are disconnected. However, due to the breadth and complexity of the application of mathematics in practical work such as economics, management, and financial analysis, it is difficult to directly apply professional application examples to economic mathematics teaching, and the examples combined with 
specialization are too superficial. These examples usually have a large degree of abstraction, and the abstraction process is usually omitted. What is shown to students is still "mathematical", which is far from practical applications.

Economic Mathematics Reform Model Changing the Teaching Method With the integration of teaching content, the economic mathematics teaching reform has gradually evolved from a simple content reorganization to a mode in which content and teaching methods are adjusted simultaneously. Various teaching methods have been continuously applied to mathematics. In teaching, this model has two typical performances: one is the introduction of multimedia-assisted teaching methods in economic mathematics; the other is the introduction of mathematical experiments and the use of some computing tools in economic mathematics teaching, making some originally complicated Mathematical calculations are programmatic and instrumental. It is worthy of simplification of tedious and lengthy mathematical calculations in the past. This reform of teaching methods and methods has also brought some new ideas to economic mathematics teaching to a certain extent. It has stimulated students' interest and enthusiasm in economic mathematics. Through multimedia and mathematics software teaching, I found that although multimedia teaching has many advantages, such as: intuitive, lively, and large classroom capacity, students don't have much time to understand and think in the classroom, so they don't understand mathematical content thoroughly. It is also mechanical for mathematical software applications.

\section{Thoughts on Teaching Reform of Economic Mathematics}

Set up science courses The three courses of calculus, linear algebra, and probability statistics are required courses for the first and second grades of the university. The total credits should not be less than 14 credits. In order to make economic mathematics courses better serve subsequent courses, you can consider arranging elective courses in the last year, such as: mathematical modeling, mathematical experiments, complex function, operations research, etc. The connection will inspire students to use mathematical knowledge to solve practical problems encountered in professional practice, strengthen students' mathematical application consciousness and ability, and cultivate their innovative spirit and ability.

Selecting teaching content The choice of economic mathematics curriculum content should be conducive to the cultivation of students' mathematical thinking methods and the development of mathematical ability, so that students have a higher mathematical quality to engage in the study of economic problems. Economic mathematics as a basic course not only requires students to learn mathematics, but also enables students to learn to use mathematics. The focus is on three aspects: First, there is a choice between strict mathematical definitions, abstract theorems, propositions, complex proofs, and calculations. The knowledge area should be wider, and the difficulty requirements for each knowledge point can be lower. Second, the definitions, concepts, and rules that are highly ideological and difficult to understand should be introduced and analyzed as much as possible, so that students can understand the creative thinking process while deepening their understanding. The third is some mathematical concepts that are closely related to economics, such as: functions, derivatives, differentiation, integration, elasticity, margins, matrices, probability, etc., more about application cases, more about the background and process in which they were originally connected, learning to use mathematics at the same time cultivates students' courage to explore mathematics. In short, our students do not have to experience the depth of mathematics, but they must appreciate the breadth of mathematics, understand modern mathematical thought, and dare to apply it to practical economic problems.

Reform of teaching methods and teaching methods Due to the large amount of economic mathematics information, high abstraction, and complex content, the teaching objects are lower grades, and the class forms are large classes. Therefore, the teaching methods and teaching methods are very important. Teachers should try to incorporate heuristics as much as possible in teaching, and constantly raise questions, create backgrounds, and inspire students to analyze and solve problems. Therefore, the most important thing in economic mathematics teaching is to deal with the relationship between teacher leadership and student initiative. In addition, teachers should cultivate 
students 'rational spirit with the humanistic spirit of mathematics, discuss issues with students on an equal footing, and encourage them to ask more questions, express their opinions differently, and carefully discover and affirm students' innovations. Younger students who have just entered university have a great influence, so teachers should strive to be good teachers and friends of students. With the popularization of computers, more mathematics courseware should be used for auxiliary teaching with the help of computers. This will increase the classroom capacity, make more abstract content more intuitive through graphics, animation and other presentations, and deepen students' understanding. In the teaching, we must gradually use mathematics teaching software such as Matlab, Mathematica, etc. After the class, we will use experiments to enhance students' practical ability and improve learning efficiency.

Introduce mathematical modeling to train students' application ability. Due to the rapid development of computers, solving problems in natural sciences, engineering technology, and social sciences through mathematical modeling has become a widely used method. Modeling starts with the application. Through the teaching and learning of mathematical modeling, provide an environment for students to learn and use mathematics, provide students with the opportunity to learn independently, explore independently, ask questions, and solve problems independently. Try to provide students with different levels to show them The stage of creativity enables them to learn mathematics and use mathematics in the process of problem solving to strengthen their understanding of mathematics. From the past emphasis on the "useful and usable" of mathematical knowledge, to enabling students to "learn what they have learned" I want to use, can use and can use. " This encourages divergent thinking, induces creative ability, embeds mathematics in the cognitive process of activities, rather than accumulation of dead knowledge, and allows students to be more exposed to such problems, and to cultivate their awareness and ability to use mathematics and stimulate them to learn mathematics. Interest and enthusiasm to help them learn and live mathematical theory knowledge and improve their comprehensive ability will undoubtedly have a positive impact.

Strengthening the construction of the teaching staff. To build a teaching staff with a high teaching level and strong scientific research capabilities, and a reasonable level of education and age structure. In order to do this work, first of all, we must pay attention to "passing, helping, and leading” young teachers. Secondly, we pay attention to the mutual learning and mutual consultation among old, middle and young teachers. Teaching seminars are held from time to time to study and discuss new problems found in teaching work, and put forward specific requirements for each teacher's lectures. Teachers are encouraged to write teaching research papers, and have different requirements for the number of essays officially published by teachers with different professional titles, and it is listed as one of the important basis for year-end assessment and professional title promotion. Finally, pay attention to the relationship between teaching and scientific research. In fact, teaching and research are closely related, mutually reinforcing, mutually reinforcing and mutually reinforcing. Because attaching importance to scientific research and doing a good job in scientific research can not only improve the quality and academic level of the teaching staff, but also create favorable conditions for promoting the reform of higher mathematics teaching and improving the quality of teaching.

\section{Conclusion}

The reform of economics mathematics courses in economics and management in colleges and universities is a long-term and continuous improvement process, and it is related to the long-term development of colleges and universities. We should constantly practice and summarize, and make unremitting efforts to establish a mathematics teaching system that is suitable for the development of modern economics and management professional education.

\section{Acknowledgements}

Xi'an Eurasian College Key Course Construction Fund Project (2018KC032) 


\section{References}

[1] Lu Chunyan. Some Thoughts on the Reform of Higher Vocational Economic Mathematics [J]. China Science and Education Innovation Leadership, 2008, (35): 104-105.

[2] Pang Shuping. Research on Economic Mathematics for Students' Professional Ability Training in Financial Colleges [J]. Shopping Mall Modernization, 2010, (2): 80-82.

[3] Cai Xia. Discussion on the Deficiency and Countermeasures of Economic Mathematics Teaching in Chinese Universities [J]. Entrepreneurs' World (Second Half-Month Edition), 2009, (10): 149-150.

[4] Ye Yingchun. On the Teaching Reform of Economic Mathematics in Higher Vocational Colleges [J]. Journal of Liaoning Administration College, 2007, 9 (6): 207-208.

[5] Sun Dehong, Zheng Senwei. On the Teaching of Economic Mathematics in Higher Vocational Colleges [J]. Journal of Hubei Radio \& TV University, 2010, 30 (7): 25. 